\title{
Interventional Study on Adherence to Pharmacotherapy and Drug Pattern in Elderly Patients at Civil Hospital of Badin, Pakistan
}

\author{
Muhammad Shehnshah¹, Mudassar Iqbal Arain², Muhammad Ali Ghoto², \\ Abdullah Dayo1, Saira Shahnaz ${ }^{3}$, and Ramesha Anwar ${ }^{4}$ \\ ${ }^{1}$ Department of Pharmaceutics, Faculty of Pharmacy, University of Sindh, Jamshoro, Pakistan \\ ${ }^{2}$ Department of Pharmacy Practice, Faculty of Pharmacy, University of Sindh, Jamshoro, Pakistan \\ ${ }^{3}$ Faculty of Pharmacy, Nazeer Hussain University, Karachi, Pakistan \\ ${ }^{4}$ Department of Pharmacy Practice, Faculty of Pharmacy, University of Karachi, Karachi, Pakistan \\ ORCID: \\ Mudassar lqbal Arain: https://orcid.org/0000-0002-1797-9927
}

Corresponding Author: Mudassar lqbal Arain; email: Mudas-

sar.arain@usindh.edu.pk

Received 05 July 2021

Accepted 09 September 2021

Published 30 September 2021

Production and Hosting by Knowledge E

(c) Muhammad Shehnshah et al.. This article is

distributed under the terms of the Creative Commons

Attribution License, which permits unrestricted use and redistribution provided that the original author and source are credited.

Editor-in-Chief:

Prof. Mohammad A. M. Ibnouf

\section{Abstract}

Background: To assess the contributing factors to adherence of pharmacotherapy and perception of elderly patients.

Methods: This prospective cross-sectional study was conducted in the outpatient clinic of Civil Hospital Badin, Pakistan from January to June 2019. A total of 300 samples were selected to analyze the results. A self-designed proforma (prescribing indicator form) was used for collecting data including patient demographics, diagnosis, and the current medications prescribed for each patient.

Results: Of the 300 selected participants, 221(73.7\%) were male, while 79 (26.3\%) were female. Majority of the subjects in the age group of 60-69 (52\%) and 70-79 years (27\%) followed by those aged $>79$ (21\%). Antibiotics were prescribed to $17.2 \%$ and vitamins to $14.7 \%$. Patients' responses related to nonadherence factor were $92.7 \%$ for the cost, $32.7 \%$ for the long treatment duration, and $24 \%$ for the lack of knowledge. Out of the total patients, $28 \%$ were forgetful, $26.7 \%$ complained about complex therapy, $26.3 \%$ blamed financial problems, $19.7 \%$ patients had side effects, and $14.3 \%$ were negligent in taking the medication.

Conclusion: Patient conformity can be enhanced by dropping polypharmacy and simplifying complex management, use of extended formulations, rate of medications, and by creating awareness among elderly patients.

Keywords: elderly, polypharmacy, pharmacotherapy, adherence

\section{Introduction}

In geriatric patients, irrational prescription of medicines has been found to be the most frequent reason of morbidity and mortality. Irrational medication is defined as: "A medicine in which the risk of an undesirable event is more, its clinical benefit, mainly when there is a safer or more useful alternate treatment for the same situation 
is available." Previous studies have shown the incidence of adverse reactions of drug are due to irrational prescription of medications [1, 2]. It is pertinent to recognize the irrational medications use in this group of population to curtail pharmacotherapy-related problems [3]. It is an important prompt factor for the conception of criteria for the harmless medicines usage in the elderly people, specifically, the beers criteria, released in 1997 and updated in 2012 and 2015 [4]. The beers criteria in geriatric, usually known as the beers list, sets out the parameters for healthcare providers to assist in the safe prescription of medicines for older adults. It emphasizes on medication prescribing which is redundant [5]. It was observed that $10-31 \%$ of geriatrics admissions in hospital emergency department were related to greater use of unnecessary medications $[5,6]$. Medications adherence generally refers to whether a patient is taking their medications as prescribed, as well as whether they continue to obtain the prescribed medicine [7]. Adherence can be defined as: "The extent to which an individual behavior corresponds with agreed recommendations from a health care provider" [8]. It is also considered that whether patients take medications according to prescribed instructions and recommendations $[9,10]$. Various factors such as patients' age and gender, socioeconomic status, severity of illness, difficulty in prescribing medication, public approval, poor patientrelated relationships, high cost, poor memory, and presence of emotional problem have been shown to influence the adherence in various populations [2]. There are five adherence-related dimensions that are considered most important in healthcare system. Societal, healthcare system-related, circumstance-related, physiotherapy-related, and patients-related. Nonadherence is a complicated problem that not only affects patients but also healthcare providers. Medication nonadherence occurs when patient fails to take medicines according to the prescribed instructions [11].

\section{Materials and Methods}

A prospective cross-sectional study was conducted in the outpatient clinic of Civil Hospital Badin, Pakistan from January to June 2019. A total of 300 samples were selected to analyze the results. A self-designed proforma (prescribing indicator form) was used for collecting data which including patient demographics, diagnosis, and current medications prescribed for each patient. Both male and female elderly patients who were taking two or more medications for any medical illness were included. Patients receiving care at home were excluded. Patients' demographic information, previous treatment history, and existing medications were distinguished in a self-predesigned proforma. Patients' relevant information were obtained from hospital records and through direct interviews 
with patients. The patients' demographic information, diagnosis, previous medical and current diagnosis with prescribed medication was arranged in patient proforma. At the end of the research, results were analyzed using the MS Excel and descriptive statistics.

\section{Results}

Out of the 300 selected participants, 221 (73.7\%) were male while 79 (26.3\%) were female. Majority of the subjects were in the age group of 60-69 (52\%) and 70-79 years (27\%), followed by those aged $>79(21 \%)$, as shown in Table 1.

TABLE 1: Demographic details of the patients (age distribution).

\begin{tabular}{|c|c|}
\hline \multicolumn{2}{|c|}{ Age distribution of patients } \\
\hline Valid (yr) & $60-69$ \\
\hline & 70-79 \\
\hline & $>79$ \\
\hline & Total \\
\hline
\end{tabular}

Frequency $(\mathbf{n})$
156
81
63
300

Percentage (\%)
$52 \%$
$27 \%$
$21 \%$
$100 \%$

Moreover, majority of patients were diagnosed with arthritis and diabetics (36\%) and heart problems, as shown in Table 2.

TABLE 2: Comorbidities among patients.

Comorbidities
Arthritis and diabetes
Heart problems and hypertension
Respiratory diseases and diabetes
Gastro-intestinal Problem
Psychological and hypertension
Eye diseases
Skin infections
Seasonal allergy
Cholecystitis
Total

\begin{tabular}{|l|l|}
\hline Frequency $(\mathbf{n})$ & Percentage (\%) \\
\hline 108 & $36.0 \%$ \\
41 & $13.7 \%$ \\
54 & $18.0 \%$ \\
34 & $11.3 \%$ \\
25 & $8.3 \%$ \\
15 & $5.0 \%$ \\
11 & $3.7 \%$ \\
9 & $3.0 \%$ \\
3 & $1.0 \%$ \\
300 & 100.0 \\
\hline
\end{tabular}

Further, majority of the patients were prescribed multiple-drug therapy. Most prescriptions had either seven (27.7\%) or six (21\%) drugs prescribed in them (Table 3).

Results showed that antibiotics were prescribed to $17.2 \%$ patients, followed by vitamins and nutritional supplement to $14.7 \%$, as shown in Table 4.

Patient's response related to nonadherence factor were $92.7 \%$ for cost, $32.7 \%$ for long duration of treatment period, and $24 \%$ for lack of knowledge about the disease (Table 5). 
TABLE 3: Drugs prescribed per prescription.

\begin{tabular}{|c|c|c|c|c|}
\hline \multicolumn{2}{|c|}{ Number of drugs } & \multirow{2}{*}{$\begin{array}{l}\text { Frequency }(\mathrm{n}) \\
7\end{array}$} & \multirow{2}{*}{$\begin{array}{l}\text { Percentage (\%) } \\
2.3\end{array}$} & \multirow[t]{2}{*}{ P-value } \\
\hline Valid & 2 drugs & & & \\
\hline & 3drug & 17 & 5.7 & \multirow{7}{*}{0.005} \\
\hline & 4drugs & 52 & 17.3 & \\
\hline & 5 drugs & 41 & 13.7 & \\
\hline & 6 drugs & 63 & 21.0 & \\
\hline & 7 drugs & 83 & 27.7 & \\
\hline & $>7$ drugs & 37 & 12.33 & \\
\hline & Total & 300 & 100.0 & \\
\hline
\end{tabular}

TABLE 4: Drug utilization pattern.

\begin{tabular}{l|l|l|}
\hline Prescribed drugs in prescription & No. of drugs (n) & Percentage (\%) \\
\hline Antibiotics & 295 & $17.2 \%$ \\
\hline Vitamins and nutritional supplements & 255 & $14.7 \%$ \\
\hline Antiprotozoal & 134 & $7.7 \%$ \\
\hline Antacid & 182 & $10.5 \%$ \\
\hline Laxatives & 112 & $6.4 \%$ \\
\hline Diuretics & 101 & $5.8 \%$ \\
\hline Analgesics & 121 & $7 \%$ \\
\hline Anti-hypertensive & 163 & $9.4 \%$ \\
\hline Cholagogues & 59 & $3.4 \%$ \\
\hline Antidiabetics & 158 & $9.1 \%$ \\
\hline Others & 150 & $8.7 \%$ \\
\hline Total & 1733 & $100 \%$
\end{tabular}

TABLE 5: Factors of nonadherence.

\begin{tabular}{|c|c|c|c|}
\hline Factors & No. of patient (300) & Percentage (\%) & P-value \\
\hline \multicolumn{4}{|l|}{ Social and economic } \\
\hline Cost of medication too expensive & 278 & $92.7 \%$ & \multirow{2}{*}{0.23} \\
\hline Illiterate & 105 & $35 \%$ & \\
\hline \multicolumn{4}{|l|}{ Therapy-related } \\
\hline Complexity of medication regimen & 121 & $40.3 \%$ & \multirow{3}{*}{0.0034} \\
\hline Long duration of treatment period & 98 & $32.7 \%$ & \\
\hline No. of medications/too many medications & 101 & $33.7 \%$ & \\
\hline \multicolumn{4}{|l|}{ Patient-related } \\
\hline Lack of knowledge about the disease & 72 & $24 \%$ & \multirow{4}{*}{0.0013} \\
\hline Failure to remember to take all the pills & 69 & $23 \%$ & \\
\hline When felt worse/bad & 41 & $13.7 \%$ & \\
\hline Decision to omit & 48 & $16 \%$ & \\
\hline
\end{tabular}

Patients related to BMQ (access screen) response showed that $66 \%$ of the patients had difficulty in obtaining medications on time but after interventions it was $59.4 \%$. 
TABLE 6: Frequency of patient's responses to BMQ (access screen).

\section{BMQ (access screen)}

Reported difficulties in reading what was written on the packet

Reported difficulty in obtaining the medications on time

Reported difficulties in taking various medicine at the same time

${ }^{*} P=<0.005,{ }^{* *} P=<0.001$.

\section{No. of patients} pre-interventions (300)

$153(51 \%)^{*}$

$198(66 \%)^{* *}$

$166(55.3 \%)^{*}$
No. of patients post-interventions (244) $150(61.5 \%)^{*}$

$145(59.4 \%)^{* *}$

$146(59.8 \%)^{* *}$

\section{Discussion}

Medication nonadherence is a complex problem, and a major public health issue. Adherence to pharmacotherapy is a primary determinant of successful therapy and considers a multi-factorial response. Clinical practitioners apply principles and adherences methods in daily practice in a similar manner for the effectual supervision of healthcare system shown in the study $[9,10]$. Majority of elderly patients in this study was male $(73.7 \%)$. Gender distribution of elderly patients has been addressed in various previous studies that have reported findings similar to ours. Although adherence to treatment involves multiple factors, age can be considered as one of the leading cause for forgetfulness and polypharmacy in relation to the comorbidities. Majority of our patients were in the age group of $60-69(52 \%)$ and $70-79$ years (27\%), followed by those aged $>79$ years $(21 \%)$, similar to the study of Fernandez et al. [28]. The noncompliance and nonadherence are influenced by the increasing age of the patients. The standard for adherence evaluation is more competent use of restricted resources for maximization of healthcare benefit at lower cost. The results of the current study showed that the majority of the patients were on multiple-drug therapy which indicates polypharmacy since $27.7 \%$ of them were prescribed six or more medicines and $21 \%$ were given more than five. Clearly, polypharmacy is the major factor contributing to the noncompliance as reported by Payne and Esmonde-White [29]. According to Schuz et al., nonadherence as difficulty in reading, in remembering time and comorbidities with multiple disease requires multiple drugs [12]. Clearly, studies on elderly people have shown that there is a need to address adherence-related problems among elderly patients [12-14]. Kharicha et al. showed that elderly people generally resist to taking medications [15-17]. Different studies support age factor as the chief reason for nonadherence [18]. The cost of the medication cannot be ignored in assessing the compliance since our study showed that it was a significant cause for the noncompliance $(92.7 \% ; p=0.23)$. Therapy-related reasons were also part of our assessment since complex regimen was found among $40.3 \%(p=0.0034)$ as 
studied by many researchers and in line with the findings of Navaratnam et al. [26]. Moreover, our study showed patients-related factors among $24 \%$, which is similar to the findings of Nikolaus et al. [19]. Polytherapy involves a multiple-drug treatment, which is quite difficult to follow. For elderly patients, the polypharmacy plays a major role as a contributing factor to nonadherence, as the results of the current study showed that $59 \%$ of the patients failed to take medication on time, which is also supported by some previous studies [20-23]. The interventions were performed to assess the response; post-intervention results showed significant changes in the reading of details about medications which was altered from $51 \%$ of the patients to $61.5 \%(p=<0.005)$. Similarly, previous interventional studies have also shown a positive response [24-26]. Various comorbidities have an express association with obedience of medication in elderly patients as patients with numerous diseases obviously require a higher complex dosing regimen, polypharmacy, and amplified medication costs [27-29].

\section{Conclusion}

The study of elderly patient for nonadherence and utilization of medicine therapies showed an association with the intensity of compliance. The patients who show regularity in follow-up sessions and attend interventional guideline generally showed better medication compliance. Standard follow-up and patient education is recommended for generating appropriate knowledge about their treatments.

\section{Acknowledgements}

The authors acknowledge all supporting staff and faculty members who guided them throughout the research work.

\section{Ethical Considerations}

The study was approved by the advance studies and research board, University of Sindh Jamshoro, Pakistan. All patients filled a consent form after receiving all information by the patients and their HCPs.

\section{Competing Interests}

The authors have no conflicts of interest to declare for this study. 


\section{Availability of Data and Material}

All relevant data and methodological details pertaining to this study are available to any interested researchers upon reasonable request to corresponding author.

\section{Funding}

None.

\section{References}

[1] Kocurek, B. (2009). Promoting medication adherence in older adults and the rest of us. Diabetes Spectrum, vol. 22, no. 2, pp. 80-84.

[2] Saleem, F., Hassali, M., Shafie, A., et al. (2012). Drug attitude and adherence: a qualitative insight of patients with hypertension. Journal of Young Pharmacists, vol. 4, no. 2, pp. 101-107.

[3] Ramanath, K. V., Balaji, D. B. S. S., Nagakishore, C. H., et al. (2012). A study on impact of clinical pharmacist interventions on medication adherence and quality of life in rural hypertensive patients. Journal of Young Pharmacists, vol. 4, no. 2, pp. 95-100.

[4] Schumaker, S. A. and Naughton, M. J. (1995). The international assessment of healthrelated quality of life: a theorical perspective. In: S. A. Schumaker and R. A. Berzon (Eds.), Quality of Life: Theory, Translation, Measurement and Analysis (pp. 3-10). Oxford: Rapid Communications.

[5] Zamora-SaÂnchez, J. J., PeÂrez-Tortajada, G., Mendoza-GarcõÂa de Paredes, M. D., et al. (2012). Quality of life perceived by complex patients in a case management program in primary health care. Enfermería Clínica, vol. 22, no. 5, pp. 239-246.

[6] BadõÂa, X., Salamero, M., Alonso, J., et al. (Eds.). (1999). Health measure. In Measurement Scales Guide in Spanish ( $2^{\text {nd }}$ ed.). Barcelona: Edimac.

[7] Tudela, L. L. (2009). Health-related quality of life. Aten Primaria, vol. 41, no. 7, pp. $411-416$.

[8] World Health Organization. (2013). Adherence to Long-term Therapies: Evidence for Action. WHO

[9] Horne, R. and Weinman, J. (1999). Patients' beliefs about prescribed medicines and their role in adherence to treatment in chronic physical illness. Journal of Psychosomatic Research, vol. 47, no. 6, pp. 555-567. 
[10] Ferrer, A., Formiga, F., Almeda, J., et al. (2010). Health-related quality of life in nonagenarians: gender, functional status and nutritional risk as associated factors. Medicina Clínica, vol. 134, no. 7, pp. 303-306.

[11] De Rivas, B., Permanyer-Miralda, G., Brotons, C., et al. (2008). Health related quality of life in unselected outpatients with heart failure across Spain in two different health care levels. Magnitude and determinants of impairment: the INCA study. Quality of Life Research, vol. 17, no. 10, pp. 1229-1238.

[12] Schuz, B., Marx, C., Wurm, S., et al. (2011). Medication beliefs predict medication adherence in older adults with multiple illnesses. Journal of Psychosomatic Research, vol. 70, no. 2, pp. 179-187.

[13] Sirey, J. A., Weinberger, M. I., Greenfield, A., et al. (2013). Medication beliefs and selfreported adherence among community-dwelling older adults. Clinical Therapeutics, vol. 35, no. 2, pp. 153-160.

[14] Rajpura, J. R. and Nayak, R. (2014). Role of illness perceptions and medication beliefs on medication compliance of elderly hypertensive cohorts. Journal of Pharmacy Practice, vol. 27, no. 1, pp. 19-24.

[15] Krauskopf, K., Federman, A. D., Kale, M. S., et al. (2015). Chronic obstructive pulmonary disease illness and medication beliefs are associated with medication adherence. COPD: Journal of Chronic Obstructive Pulmonary Disease, vol. 12, no. 2, pp. 151-164.

[16] Kalichman, S. C., Eaton, L., Kalichman, M. O., et al. (2016). Race-based medical mistrust, medication beliefs and HIV treatment adherence: test of a mediation model in people living with HIVIAIDS. Journal of Behavioral Medicine, vol. 39, no. 6, pp. 1056-1064.

[17] Rajpura, J. and Nayak, R. (2014). Medication adherence in a sample of elderly suffering from hypertension: evaluating the influence of illness perceptions, treatment beliefs, and illness burden. Journal of Managed Care Pharmacy, vol. 20, no. 1, pp. 58-65.

[18] Azpiazu, M., Cruz, A., Villagrasa, J. R., et al. (2003). Quality of life in no institutionalized persons older than 65 years in two health care districts in Madrid. Atención Primaria, vol. 31, no. 5, pp. 285-294.

[19] Van der Weele, G. M., Gussekloo, J., De Waal, M. W., et al. (2008). Co-occurrence of depression and anxiety in elderly subjects aged 90 years and its relationship with functional status, quality of life and mortality. International Journal of Geriatric Psychiatry, vol. 24, no. 6, p. 595-601. 
[20] Tjia, J., Givens, J. L., Karlawish, J. H., et al. (2008). Beneath the surface: discovering the unvoiced concerns of older adults with type 2 diabetes mellitus. Health Education Research, vol. 23, no. 1, pp. 40-52.

[21] Vermeire, E., Hearnshaw, H., Van Royen, P., et al. (2001). Patient adherence to treatment: three decades of research. A comprehensive review. Journal of Clinical Pharmacy and Therapeutics, vol. 26, pp. 331-342.

[22] Lam, W. Y. and Fresco, P. (2015). Medication adherence measures: an overview. BioMed Research International, vol. 2015, p. 217047.

[23] Brown, M. T. and Bussell, J. K. (2011). Medication adherence: WHO cares? Mayo Clinic Proceedings, vol. 86, no. 4, pp. 304-314.

[24] Johnson, M. J., Williams, M., and Marshall, E. S. (1999). Adherent and nonadherent medication-taking in elderly hypertensive patients. Clinical Nursing Research, vol. 8, no. 4, pp. 318-335.

[25] Nikolaus, T., Kruse, W., Bach, M., et al. (1996). Elderly patients' problems with medication. European Journal of Clinical Pharmacology, vol. 49, no. 4, pp. 255259.

[26] Navaratnam, P., Jayawant, S. S., Pedersen, C. A., et al. (2008). Asthma pharmacotherapy prescribing in the ambulatory population of the United States: evidence of nonadherence to national guidelines and implications for elderly people. Journal of the American Geriatrics Society, vol. 56, no. 7, pp. 1312-1317.

[27] Roy, N. T., Sajith, M., and Bansode, M. P. (2017). Assessment of Factors Associated with Low Adherence to Pharmacotherapy in Elderly Patients. Journal of Young Pharmacists, vol. 9, no. 2, pp. 272-276.

[28] Fernandez-Arias, M., Acuna-Villaorduna, A., Miranda, J. J., et al. (2014). Adherence to pharmacotherapy and medication-related beliefs in patients with hypertension in Lima, Peru. PloS ONE, vol. 9, no. 12, p. e112875.

[29] Payne, K. A. and Esmonde-White, S. (2000). Observational studies of antihypertensive medication use and compliance: is drug choice a factor in treatment adherence? Current Hypertension Reports, vol. 2, no. 6, pp. 515-524. 